\title{
EDITORIAL
}

\section{Launching of New Medical Journals}

\author{
Benash Altaf
}

These days research culture is flourishing at a break neck pace. National and international higher educational authorities are also encouraging this scientific culture. For this purpose, they are providing grants and funding. In Pakistan, Higher Education Commission (HEC), Pakistan Medical and Dental Council (PMDC) and College of Physicians and Surgeons of Pakistan (CPSP) is also facilitating undergraduate and postgraduate students and making it compulsory by giving the incentive in the form of scores to qualify for their specialized training. Similarly, they have fixed certain scores for research publications even for postgraduate doctors that without certain specified number of publications they would not be promoted. In this way, they have made it sure that this trend is kept on going in continuity. ${ }^{1}$

To cope with number of research articles coming from all over the state, initially fewer journals were there to bear all the load of research publication. Regulatory authorities have to realize this emerging issue. So they should facilitate medical institutions to launch their journals with transparent policy with a vision that it is essential to keep pace with current era in medical field. This will also help to lessen the burden of publications over the pioneer journals. Research publications are important tool for an academic career progression as it uplifts the scientific culture and give it a wind to flourish the academic foundation. Consequently, realizing the need of current era, many medical institutes are launching their journal with a vision that they would try to contribute their maximum to the medical literature. On the other hand, some researchers write just to get the fame and getting the top ranked position as described by Sultan pyramid. ${ }^{2}$ In order to maintain the scientific standard of these journals HEC has classified them into different categories in order to rank these journals as "good category", "very good" and "best" (W,X,Y,Z). These journal are not only playing a pivotal role in minimizing the rush that was once on pioneer journals but the emerging new journal also provide competitive environment to the already existing journals.

\section{Correspondence:}

Dr. Benash Altaf

Aziz Fatimah Medical \& Dental College, Faisalabad

Associate Editor JAFMDC

Email: altafbenash@gmail.com
To publish an acceptable standard scientific journal, HEC and PMDC though have formulated certain guidelines and policies which are to be followed by new journals. This was good in aspect of maintaining and raising the literature standard thence ultimately hiking the number of citations. ${ }^{3}$ Still certain policies are still not in descriptive format. In a result, some journals failed to full fill this vision and were unsuccessful in contributing the standard medical literature. PMDC should play crucial role over here by keeping check and balance on the journals. They however, derecognized, and even stop the publication of some journals. But PMDC role does not just ends here, as still some previously recognized journals are still publishing their journal whose standards are now not up to the mark.

They are still continuously publishing articles with scientific limitations. ${ }^{4}$ These include biased peer review, ethical and similarity checking issues, formatting flaws that must be checked by the editorial team. Most probably there aim is not more to provide the quality medical literature but are publishing article in context just to up lift the curriculum vitae of their personnel or just to launch numbers of issues for the business purpose. $^{5}$

So these journals before launching their new issues must improve all shortcomings by properly following the editorial process to meet the international standards. It also requires high quality manuscript with proper peer reviewed policies and these rules should not be compromised. Moreover, it is the duty of institute to realize it as a noble ethical responsibility to which an institute must consider itself to be accountable. Furtherly, here implies the duty of experienced editors from all over the world to play their role for uplifting the ethical and moral values of new editors that should not be compromised at any cost. ${ }^{6}$ PMDC should also instead of derecognizing the journals must provide the author with ample of opportunities for their publications. $^{5}$

Hence, these authorities must encourage new journals but with proper check and balance policies as full protocol followed published journal will also help to uplift our research ranking. PMDC should describe this protocol in the form of structured policies, formatting pattern and printing quality in a black and white format that the journal must have to follow before getting it published. 
These policies should be equally implemented on all the journals for the integrity of the standard. In this way, new institutes would not face problems in getting their journal recognized. These steps will help to encourage the marvelous writers and valued researches to bring them out in front of the world that will definitely make feel them symbol of honor and proud for the nation. ${ }^{7}$

\section{Conflicts of Interest: None.}

\section{REFERENCES}

1. Mushtaq A, Fatimah R, Rehman A. Medical students and medical research in Pakistan. J Pak Med Assoc. 2012; 62 (5):527-528.
2. Meo SA. Anatomy and physiology of scientific paper. Saudi J Bio Sci.2018; 25(7):1278-1283

3. Meo SA, Jawed SA. Pakistan's Performance in Global Impact Factor Race. Pak J Med Sci. 2018; 34(4):777-780.

4. Jawed SA. Professional in medical journalism and role of HEC, PM\&DC. Ann King Edward Med Uni. 2016; 22(3): 164-166

5. Jawaid SA. Authors- the most dangerous pressure group. Pak J Med Sci 2014; 30 (6):1177-1179

6. Kothari R, Bokariya P, Nongrum SM, Singh R. An account on the count of mushrooming journals. Int J Clin Exp Physiol 2018; 5:54-55

7. Ahmad B, Husain AA, Dossani K. Impact factor of Pakistani medical journal. J Pak Med Assoc. 2013; 31(1):131 